\title{
Direct injection of water mist in an intake manifold spark ignition engine
}

\author{
A.R. Babu ${ }^{*}$, G. Amba Prasad Rao' ${ }^{1}$ and T. Hari Prasad ${ }^{2}$ \\ ${ }^{1}$ Department of Mechanical Engineering, NIT, Warangal, 506004, India \\ *Email: arbabu.1973@gmail.com \\ Phone: +919581993346; Fax: +918572245126 \\ ${ }^{2}$ Department of Mechanical Engineering, SVEC, Tirupati, 5171024, India
}

\begin{abstract}
The purpose of this study is to investigate the effects of water mist (WM) injected directly into an intake manifold spark ignition (SI) engine. WM flows through a nozzle at the throttle body of the four-cylinder four-stroke multi-point injection engine for testing the performance of exhaust emission system. The water is pumped in mist form into the intake manifold with an air-fuel mixture through the nozzle, which is located on the throttle body. Experimental work and simulation methods are combined by the presence and absence of WM addition, and the performance as well as emission produced by the engine is analyzed. The Gamma Technologies (GT) methods are used to simulate the model with and without WM addition. The experimental results indicate that the standard engine performance can be used to validate the simulation model. The engine measures include various parameters such as brake power, torque, volumetric efficiency, spark advance timing, and the concentration of $\mathrm{CO}$ and $\mathrm{NO}_{\mathrm{x}}$ with water and without water addition to the SI engine (i.e., the power, torque, volumetric efficiency of the engine is increased up to $10 \%$ ). The emission of $\mathrm{NO}_{\mathrm{x}}$ is found to be significantly reduced and that of $\mathrm{CO}$ does not change.
\end{abstract}

Keywords: $\mathrm{NO}_{\mathrm{x}}$ emission; water mist; GT-simulation modeling.

\section{INTRODUCTION}

In the present study, the performance, fuel consumption, and emission of a spark ignition (SI) fuel injection system is investigated [1-3] and evaluated by adding a small amount of water mist (WM) through the intake manifold to the EFI system of a fourstroke SI engine. In IC engines, water injection, also known as Anti-Detonant Injection (ADI), is a method for cooling the combustion chambers of engines by adding water to the cylinder or incoming fuel-air mixture, generally enabling greater compression ratios and essentially eliminating the problem of knocking [4]. Water injection is not a novel concept. Introduced in IC engines during the 1920s, water injection was a key enabler of high speed IC engines in the early 1930s. When calibrated engines are operated with a small amount of water, knocking can be suppressed, hydrocarbon emissions become slightly higher, $\mathrm{NO}_{\mathrm{x}}$ emissions decrease, $\mathrm{CO}$ emission does not change significantly, and fuel and energy consumption increase [5]. Further, water gasoline fuels have higher octane ratings that can increase engine performance and decrease $\mathrm{NO}_{\mathrm{x}}$ emissions $[6,7]$. It is predicted that the water injection method will increase the octane level (replacement of the primary antiknocking additive in petroleum refining technology) and reduce $\mathrm{NO}_{\mathrm{x}}$ emissions in exhaust gas [8]. An aqueous fuel comprising water and gasoline has approximately half-potential energy (BTU's) gasoline, but when used to 
operate an internal combustion engine, it will produce approximately as much power as compared with the same amount of gasoline. The use of water fuel emulsion for controlled $\mathrm{NO}_{\mathrm{x}}$ emission can be described in the following manner [9]. Pre-ignition and detonation is suppressed by water addition: Aqueous fuel is vaporized by the water component as steam in the combustion chamber. The expansion of the steam together with the combustion of the hydrogen released by dissociation of the water molecule results in the generation of the required power output necessary for satisfactory operation of the engine [10].

The water injection lowers the compression temperatures through the latent heat of vaporization of the liquid water to gaseous form. The low-temperature water injected air/fuel or enriched $\mathrm{O}_{2}$ air/fuel mass demands less work in the compression stroke, thereby increasing overall efficiency. It also promotes increased mass flow through the engine for increased power output and efficiency [11]. In Aquamist's water injection system, the water is injected into the intake manifold and the internal temperature is reduced, as the heat from the incoming intake stream is immediately absorbed from the incoming intake stream, helping cool the hot intake charge; the rest of the atomized water becomes steam in the combustion chamber and absorbs even more heat to dramatically lower the temperature and, therefore, better control the combustion. Moreover, to suppress the detonation, the power output of the engine is increased by $3.8 \%-14 \%$, when the base fuel contains $5 \%-15 \%$ of water [12]. Further, $\mathrm{NO}_{2}$ and $\mathrm{CO}$ also reduce with water addition: the amount of water injection is equal to the fuel flow and causes an increase of approximately $20 \%$ in hydrocarbon emission in the exhaust gases. The water injection reduces the full-load petrol consumption of the concept engine by $15 \%-25 \%$ and significantly reduces the $\mathrm{HC}$ and $\mathrm{NO}_{\mathrm{x}}$ emission.

The presence of water in the intake air also reduces oxides of nitrogen $\left(\mathrm{NO}_{\mathrm{x}}\right.$ and $\mathrm{NO}_{2}$ ) and $\mathrm{CO}$ emissions, which supports the fact that the water addition to the intake manifold will reduce emissions $[13,14]$. The $\mathrm{NO}_{\mathrm{x}}$ emissions from a gasoline engine are reduced by mixing water in the gasoline to reduce combustion temperatures. The water is dispersed in the gasoline as the gasoline is delivered to the cylinders [15]. With regard to fuel consumption, when an engine is operated using LPG and water is injected into the intake manifold, the specific fuel consumption decreases, while the engine thermal efficiency increases. This increase may be because of the cooling effect of water, which acts to decrease the temperature of fresh air fuel charge in the inlet manifold as a supercharging effect, so that there is more efficient combustion as compared to the pure LPG-fueled automotive [16]. However, control over the water injection is important. It needs to be injected only when the engine is heavily loaded and the throttle is wide open. In this study, small amounts of water mist is injected through the intake manifold to analyze the performance of and emissions from a standard engine, rather than merely retrofitting of old engines, as is done these days. Some preliminary simulations are proposed here by using the GT-SUITE [17] code [17]. These simulations are used to generate new ideas more than to accurately reproduce the operation of an engine with novel water mist injection that clearly requires an experimental campaign. Direct water injection in a novel four-stroke engine with direct injection also of fuel and oxygen is considered in [18-21]. In this case, the directly injected water mist (vaporization) and steam expansion significantly increases the pressure work done by the aces on the piston, thereby increasing fuel conversion efficiency. 


\section{EXPERIMENTAL SETUP}

\section{Modeling Specifications}

A diagram of the experimental setup is presented in Figure 1. A CAMPRO 1.6 IAFM engine, which is a four-stroke, fuel injection engine cylinder is coupled with a dynamometer $(150 \mathrm{~kW})$; it helps to measure the engine torque through the part load test due to high vacuum pressure in the intake manifold, and assists the water mist pump in the combustion chamber. Standard instruments are used to measure the engine power, torque, injection timing, and pressure of oil, barometric, intake manifold, coolant inlet, exhaust, plenum and temperature of air intake, engine oil, water coolant, exhaust, as well as BSFC and percentage of relative humidity. Table 1 presents CAMPRO 1.6 IAFM SI engine specifications.

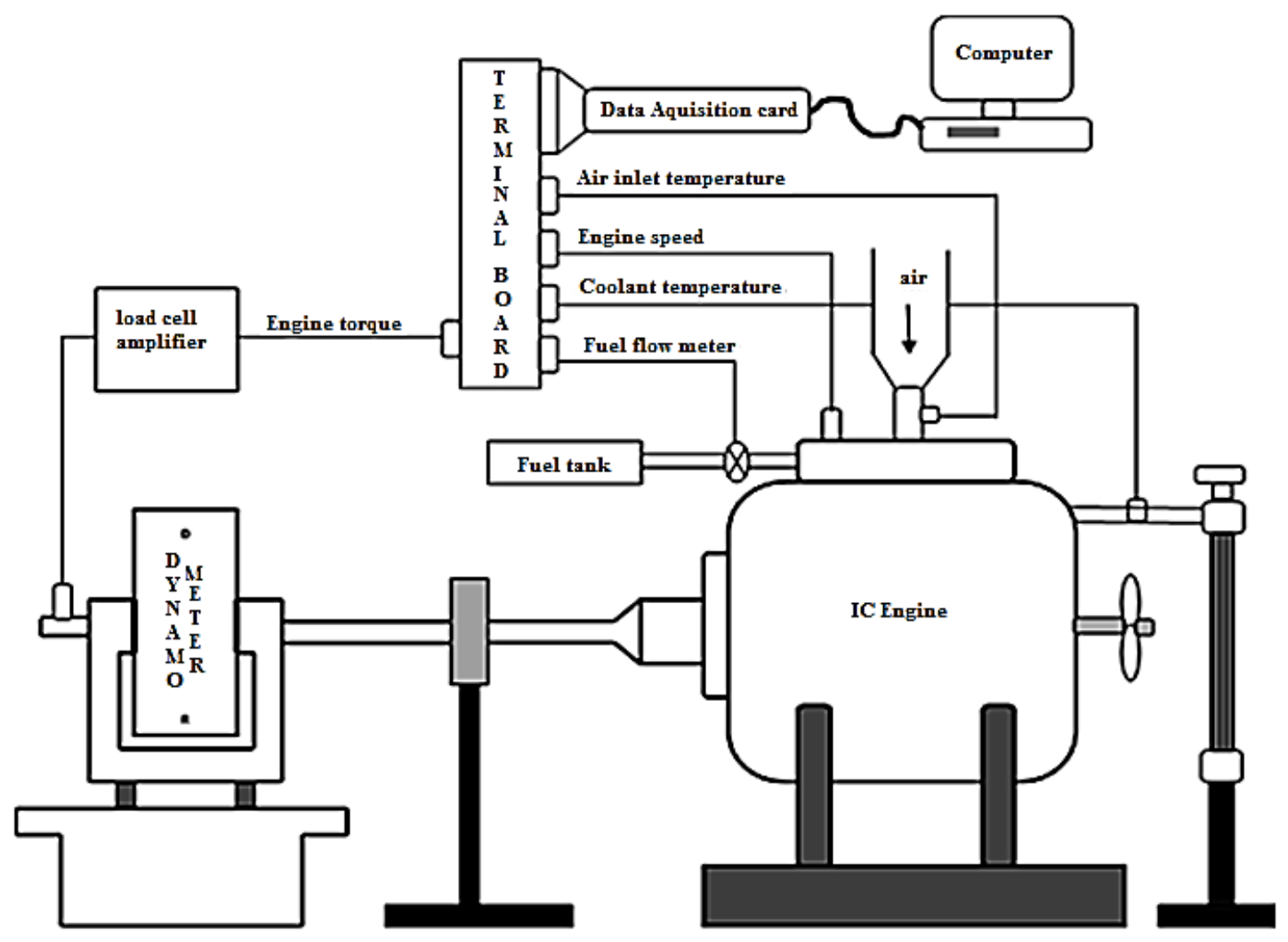

Figure 1. Schematic diagram of experimental test rig setup.

Table 1. CAMPRO 1.6 IAFM SI engine parameters.

\begin{tabular}{lc}
\hline Engine parameters & Specifications \\
\hline Bore $(\mathrm{cm})$ & 7.6 \\
Stroke $(\mathrm{cm})$ & 8.8 \\
Displacement $(\mathrm{cc})$ & 1597 \\
Compression ratio & $10: 1$ \\
Power & $110 \mathrm{Hp}(82 \mathrm{~kW}) 65500 \mathrm{rpm}$ \\
Torque & $148 \mathrm{Nm}, 1000-4000 \mathrm{rpm}$ \\
Valve mechanism & 16 valve IAFM DOHC \\
\hline
\end{tabular}




\section{Experimental Procedure}

A 1.6 IAFM in-line four-cylinder four-stroke multi-point injection engine, was used. The emission results data was obtained using Bosch-BEA 250 with DTM plus (petrol) exhaust gas analyzer. The engine speed starts from 1000rpm to 4500rpm without adding water mist with different load factors, such as $0.3,0.4,0.5$, and 0.6. This test was repeated by advancing the ignition timing and increasing the engine speed. During the testing, the data for engine torque, brake-specific fuel consumption, throttle position, exhaust temperature, plenum temperature, air intake temperature, fuel mass flow rate, barometric pressure, ignition timing etc. was recorded. The final results were acquired from the average of two stable and continuously measured values, which do not vary by more than $2 \%$. All the data were used for validation and comparison with engine testing with and without water mist addition; recorded data was automatically calculated by the software, including the main parameters (torque, brake power, fuel mass flow rate, specific fuel consumption, and exhaust temperature). The non-dispersive infrared [18] spectroscopy is used to measure $\mathrm{CO}, \mathrm{CO}_{2}$, and $\mathrm{HC}$. Warm-up is approximately $1 \mathrm{~min}$; null balance - the gas analyzer switches a solenoid valve to ambient air for system check. Zero gas is then purged for a period of $30 \mathrm{sec}$; ambient air intake is cleaned of hydrocarbons by an activated-carbon filter. Air fuel ratio measurement $(\lambda)$ includes the measured concentration of $\mathrm{HC}, \mathrm{CO}, \mathrm{CO}_{2}$, and $\mathrm{O}_{2}$. The exact oxygen content is measured on the basis of the Brettschneider Eq. (1). The testing yields accurate and reliable results, and these are analyzed to confirm that the data measurement is close to the typical reading of an internal four-stroke SI EFI engine with a catalytic converter. Engine efficiency is presented in Table 2.

$$
\lambda=\frac{\left[\mathrm{CO}_{2}\right]+\frac{[\mathrm{CO}]}{2}+\left[\mathrm{O}_{2}\right]+\left[\left[\frac{\mathrm{H}_{c v}}{4}\right] \times \frac{3.5}{\left.3.5+\frac{[\mathrm{CO}]}{\mathrm{CO}}-\frac{\mathrm{O}_{c v}}{2}\right] \times\left(\left[\mathrm{CO}_{2}\right]+[\mathrm{CO}]\right)}\right.}{\left[1+\frac{\mathrm{H}_{c v}}{4}-\frac{\mathrm{O}_{c v}}{2}\right] \times\left(\left[\mathrm{CO}_{2}\right]+[\mathrm{CO}]+K_{1}[\mathrm{HC}]\right)}
$$

where, $K_{l}$ is the conversion factor; $H_{c v}$ is the hydrogen carbon ratio in the fuel; $O_{c v}$ is the oxygen carbon ratio in the fuel; $\mathrm{O}_{2}$ is the oxygen.

Table 2. Typical emission readings.

\begin{tabular}{lc}
\hline \multicolumn{1}{c}{ Engine parameters } & Percentage/Volume \\
\hline Carbon monoxide $(\mathrm{CO})$ & $0-0.5 \%$ \\
Hydrocarbon $(\mathrm{HC})$ & $0-50 \mathrm{ppm}$ \\
Carbon dioxide $\left(\mathrm{CO}_{2}\right)$ & $14-15.5 \%$ by volume \\
Oxygen $\left(\mathrm{O}_{2}\right)$ & $1-2 \%$ by volume \\
Nitric Oxide (NO) & Various with engine loading \\
Air Fuel ratio & $0.5-9.99$ \\
\hline
\end{tabular}




\section{NUMERICAL MODELING}

Once the validation is successfully done, the engine performance simulations were conducted with the GT-SUITE code [17] for a 1.6 IAFM in-line four-cylinder fourstroke multi-point injection engine; this model will be the main source for the next analysis. The relative error between the measured data of the experiment and the simulated model are presented in Eq. (2). The commercial software GT-POWER [17] is used to preliminarily model the engine operation with WM injection upstream of the engine cylinder. The expected trends are those measured by the aftermarket suppliers of WM injection systems for the SI engine; this validation clearly does not require a more detailed description of the novel design of the WM injection system for an SI engine. Engine mapping and computational modeling are presented in Figure 2 and 3 respectively.

$$
\text { Error }_{\text {relative }}=\left[\frac{(29.04-26.1)}{29.04}\right] \times 100=10.12 \%
$$

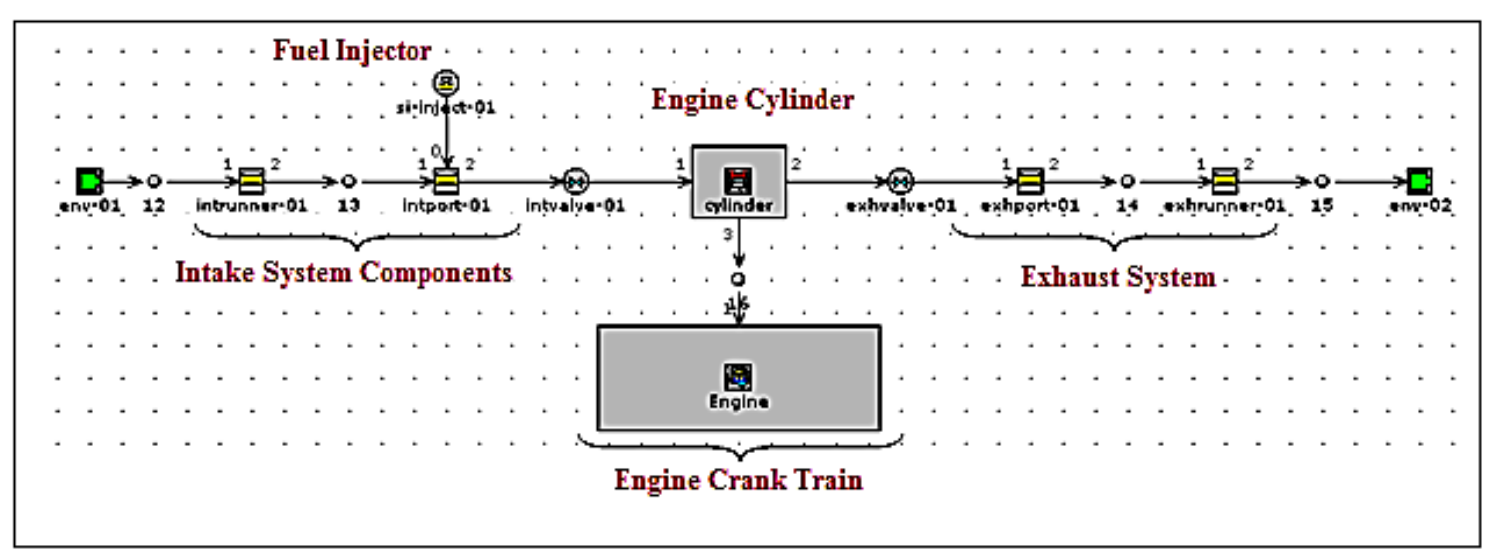

Figure 2. Project map.

The evaporation of water, expansion of steam, condensation of steam, interaction with the walls, and combustion evolution in the presence of water and steam all require an accurate validated model. This option takes into account the respective enthalpies of evaporation, condensation, partial volume (Amagat's law), and the mass of injected water to determine the dew points and humidity, saturation, precipitation, and displacement of water under the resulting temperature and prevailing pressure in the charge gas mixture.

\section{RESULTS AND DISCUSSION}

Figure 4 presents the reliability of adding WM into an SI engine. To analyze positive and negative aspects, we compare the simulation model and experimental design, when the mass flow rate is controlled. Due to the adjustment of the fuel burning rate of the engine, it is beneficial to compare the simulation results with those of the experimental design. Commercial software is used to preliminarily model engine operation with water mist injection through the intake manifold of the engine cylinder. The expected trends are those measured by the aftermarket suppliers of WM injection systems for intake manifold gasoline engines, for example [17]. This validation clearly does not require a 
more detailed discussion of the novel design of water injection systems for turbocharged gasoline engines. The very basic model proposed here is used only to develop new ideas that will be ultimately tested in an experimental campaign. No attempt is made to make the model more sophisticated, because it is very well understood than any further study should be based mostly on new experiments on nonconventional applications and additional relevant phenomena vs. the standard engine, which may be numerous and complicated [4].

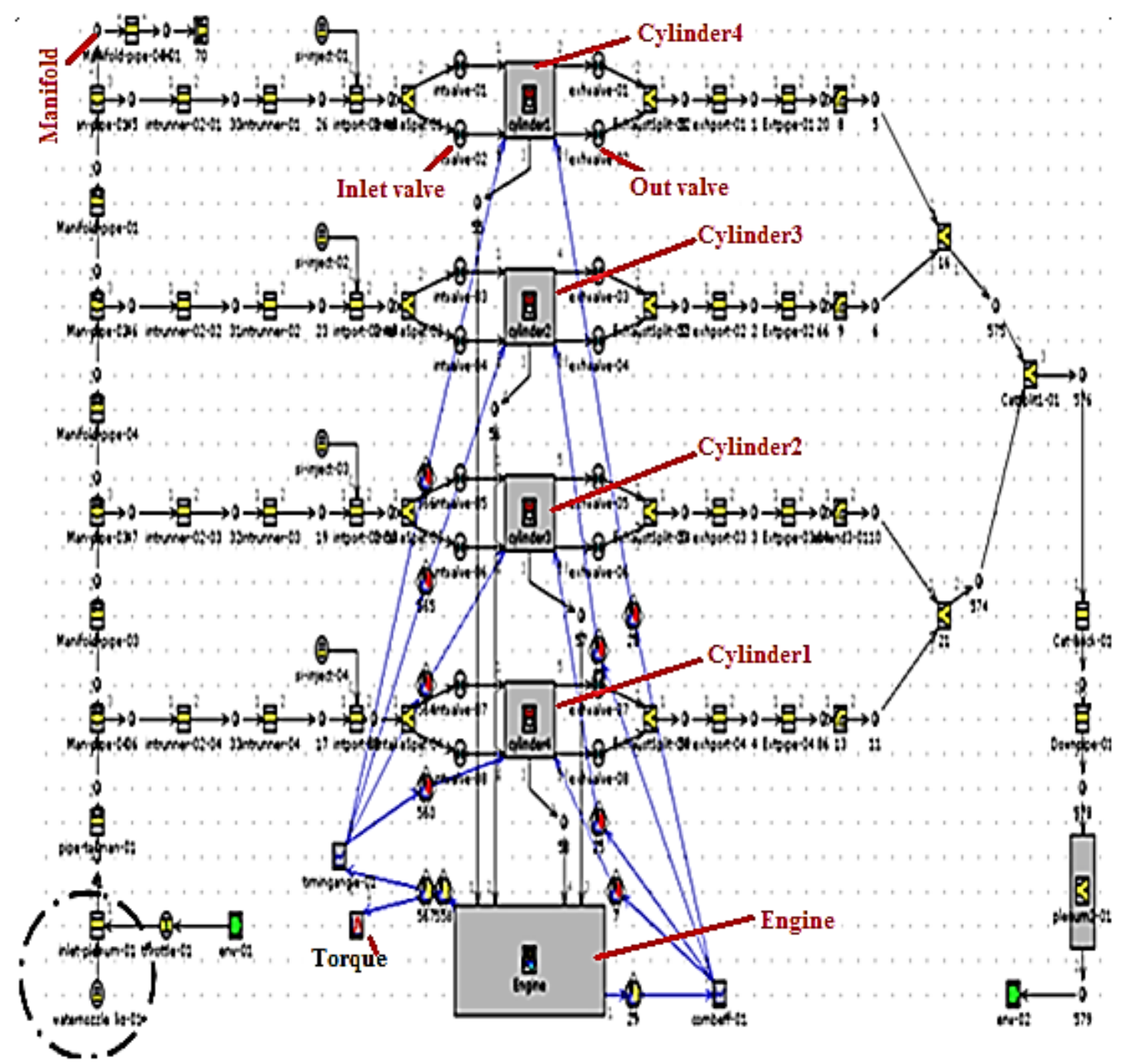

Figure 3. Computational model.

The evaporation of water, expansion of steam, condensation of steam, interaction with the walls, and combustion evolution in the presence of WM and steam all require an accurate validated model. A similarly mild validation is proposed in [22] for the case of water injection upstream of the cylinder of a diesel engine. To introduce a feature in the pipe object to deal correctly with the evaporation and condensation of water. Despite some issues, the in-cylinder results reveal an expected slight increase in the heat transfer coefficient with water injection, reduced exhaust gas temperature, peak cylinder pressure, and wall heat flux. Certain indicators such as compression polytrophic exponent, gas temperature, and heat transfer coefficient appear to suggest 
that the software captured the physics correctly [22]. When WM is injected into the system, the engine performance increases at various speeds of torque by $25 \%-30 \%$, as depicted in Figure 5. With different load factors - 0.3, 0.4, 0.5, and 0.6-and a wide open throttle, the speed of the engine is maintained and then gradually increases from $1500 \mathrm{rpm}$ to $4500 \mathrm{rpm}$.

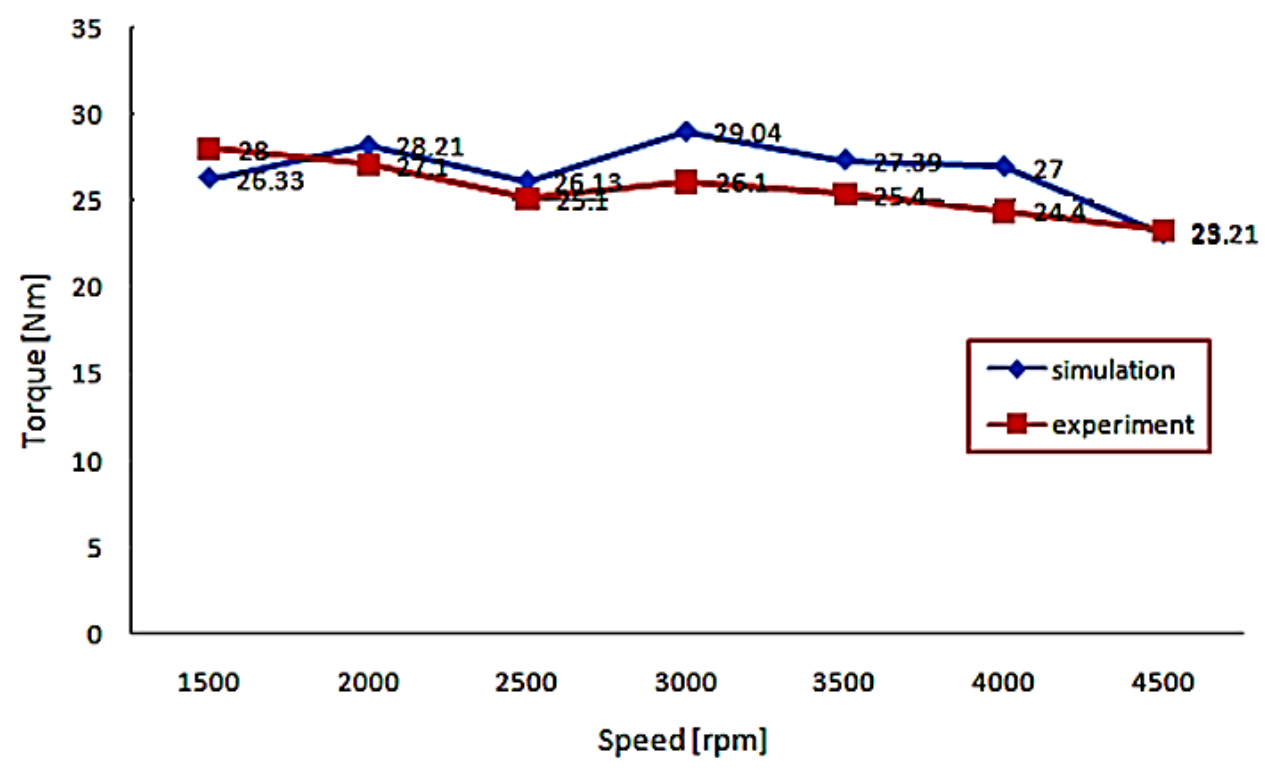

Figure 4. Comparison of the simulation results with the experimental design.

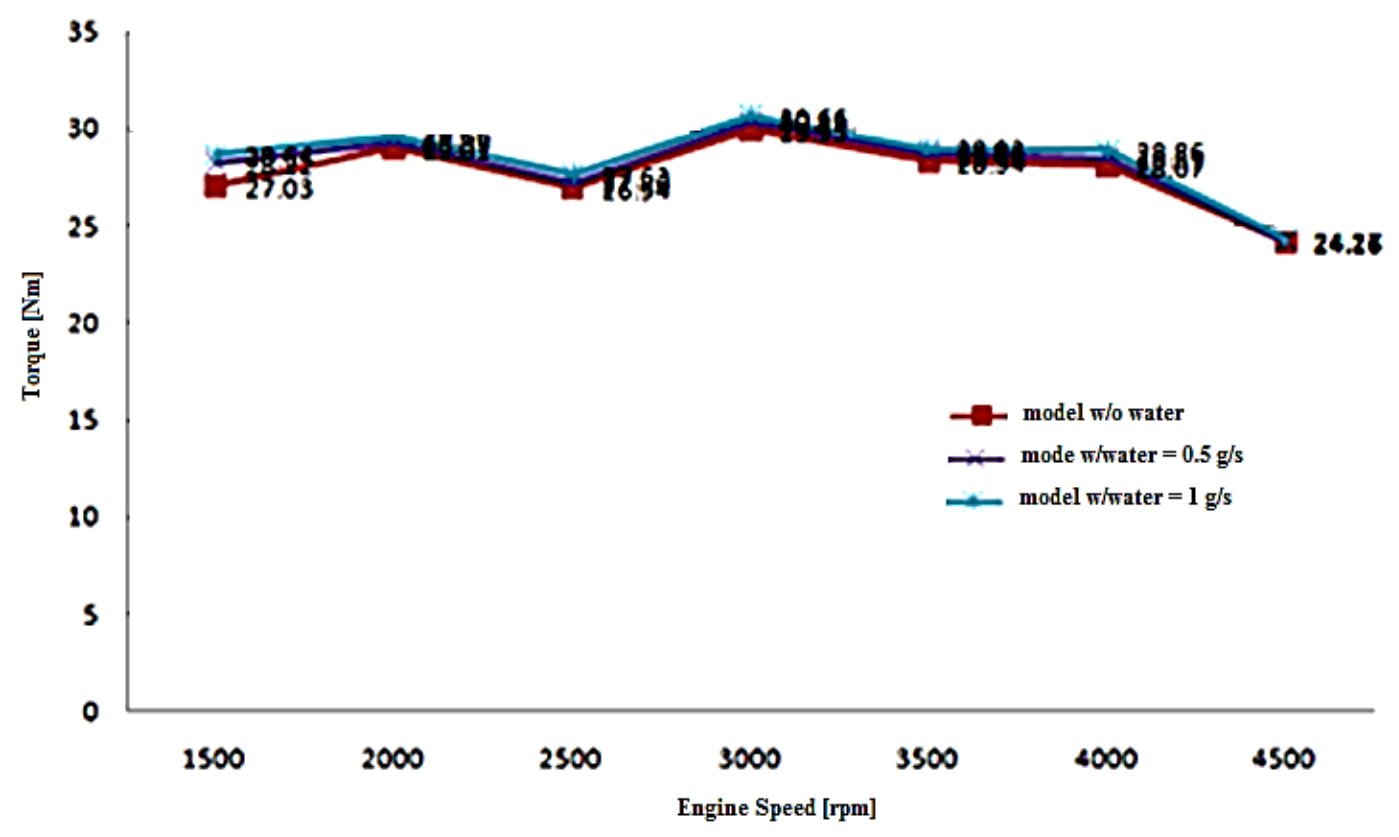

Figure 5. Comparison of results with and without the WM injection method.

The increase in the engine performance is mainly due to the dissociation of water into molecules of hydrogen and oxygen that assists combustion in the combustion chamber. When water is added to the CAMPRO engine, it can save a lot of time since the quantity of water to be added into the system has been identified. Further, the 
exhaust emission was examined in the experimental setup for emissions of $\mathrm{CO}, \mathrm{NO}_{\mathrm{x}}$, $\mathrm{CO}_{2}$, and $\mathrm{HC}$ to study the effect of water addition on the SI engine. The maximum torque increases by $10 \%-14 \%$ when water mist is injected into the engine and increases power in the range of 1500rpm-3250 rpm, as shown in Figure 6.

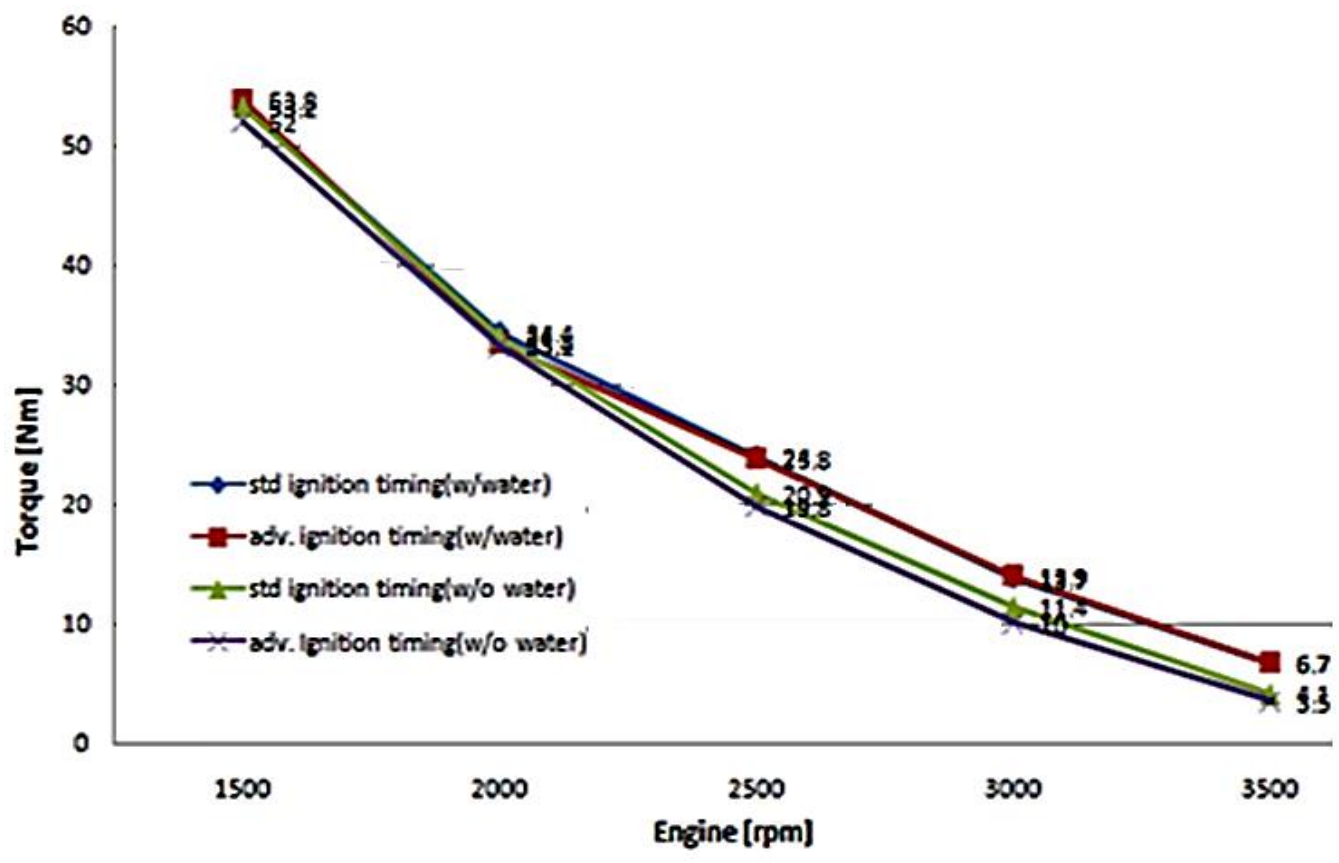

Figure 6. Ignition timing of engine with and without the WM injection method

A small adjustment is made to the temperature of the spark plug to ignite the $\mathrm{A} / \mathrm{F}$ mixture through the multipoint injection system and this is controlled by an electronic control device. It is shown that the advance ignition timing is approximately $6^{\circ}$, every time the speed of the engine is increased gradually such as $1500 \mathrm{rpm}, 2000$ $\mathrm{rpm}, 3000 \mathrm{rpm}, 3500 \mathrm{rpm}, 4000 \mathrm{rpm}$, and 4500rpm at 0.3 load condition only. The advance of ignition timing does not have any effect on the engine performance when $\mathrm{WM}$ is injected into the system; this implies that the quantity of WM that enters into the combustion chamber is not sufficient and reduces the torque of the engine. The engine performance improves with the addition of WM, because of the high volumetric efficiency of the dissociation of water converted into hydrogen and oxygen. To obtain the fuel consumption rate with and without addition of WM, the throttle angle is fixed and only the load factors of the engine are varied in the range of $1500 \mathrm{rpm}$ to $4500 \mathrm{rpm}$. To reduce the testing, the load 0.3 with water addition and the other load factor for maintain with and without water addition to the engine. Figure 7 Indicates that the lowest fuel consumption began at $1500 \mathrm{rpm}$ to $3000 \mathrm{rpm}$. At the $0.3 \mathrm{load}$ factor, the functional results are more accurate as compared with other load factors.

The NO concentration in the emission of the engine exhaust with WM addition is lower than that without WM addition to the SI engine, with no load operating condition. Figure 8 depicts that when the engine speed increases, there is an increase in NO formation; this, in turn, produces a high temperature, which causes the formation of $\mathrm{NO}_{\mathrm{x}}$. Further, $\mathrm{CO}$ emissions with WM addition are lower than without water addition; thus, with the addition of WM to the SI engine does not have too much affect on CO emissions, as shown in Figure 9. CO is produced due to incomplete combustion caused 
by insufficient amount of air in the $\mathrm{A} / \mathrm{F}$ mixture or insufficient time in the cycle for completion of combustion.

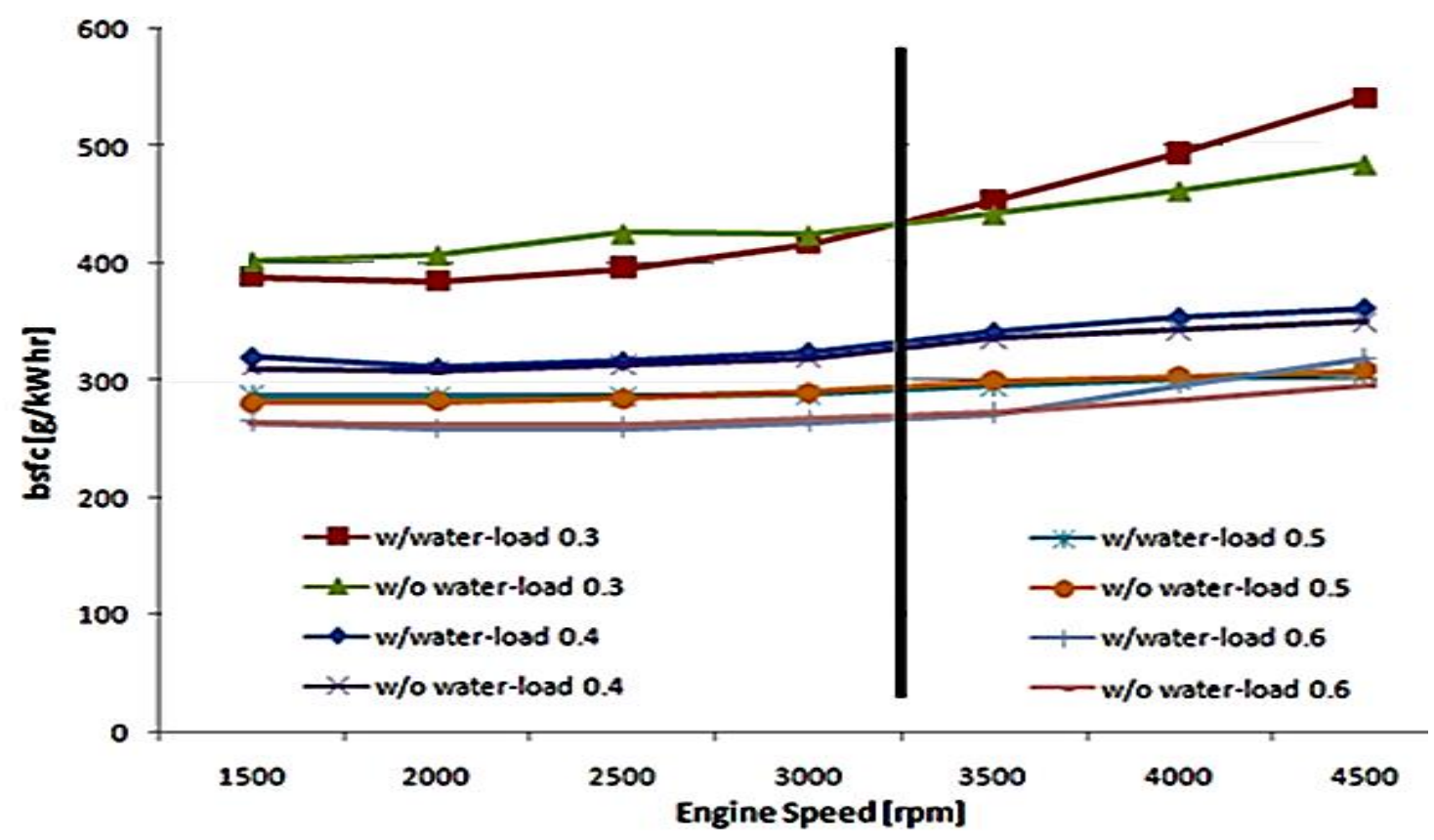

Figure 7. Brake-specific flow consumption with and without WM injection.

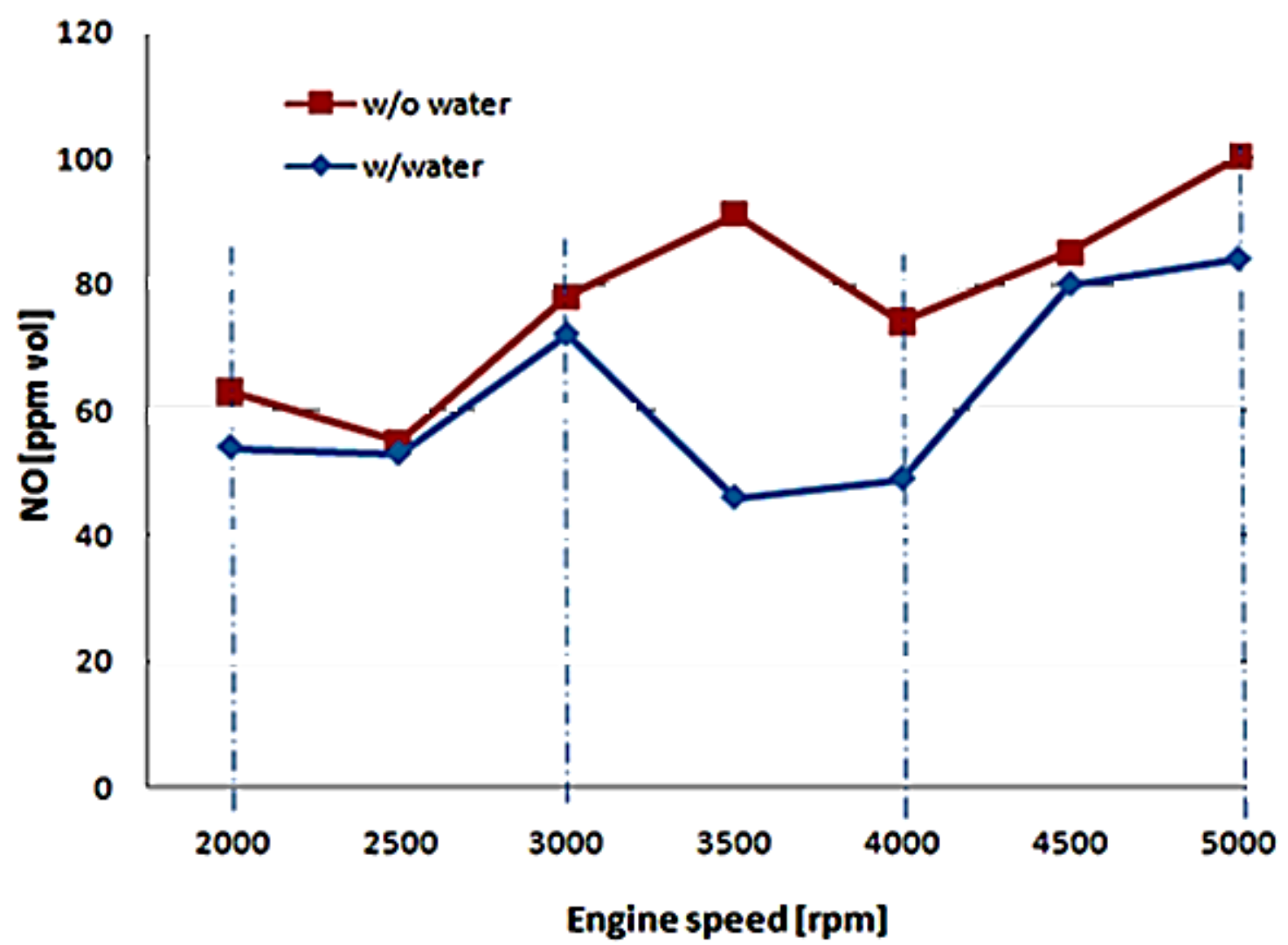

Figure 8. $\mathrm{NO}_{\mathrm{x}}$ emission with and without WM injection. 


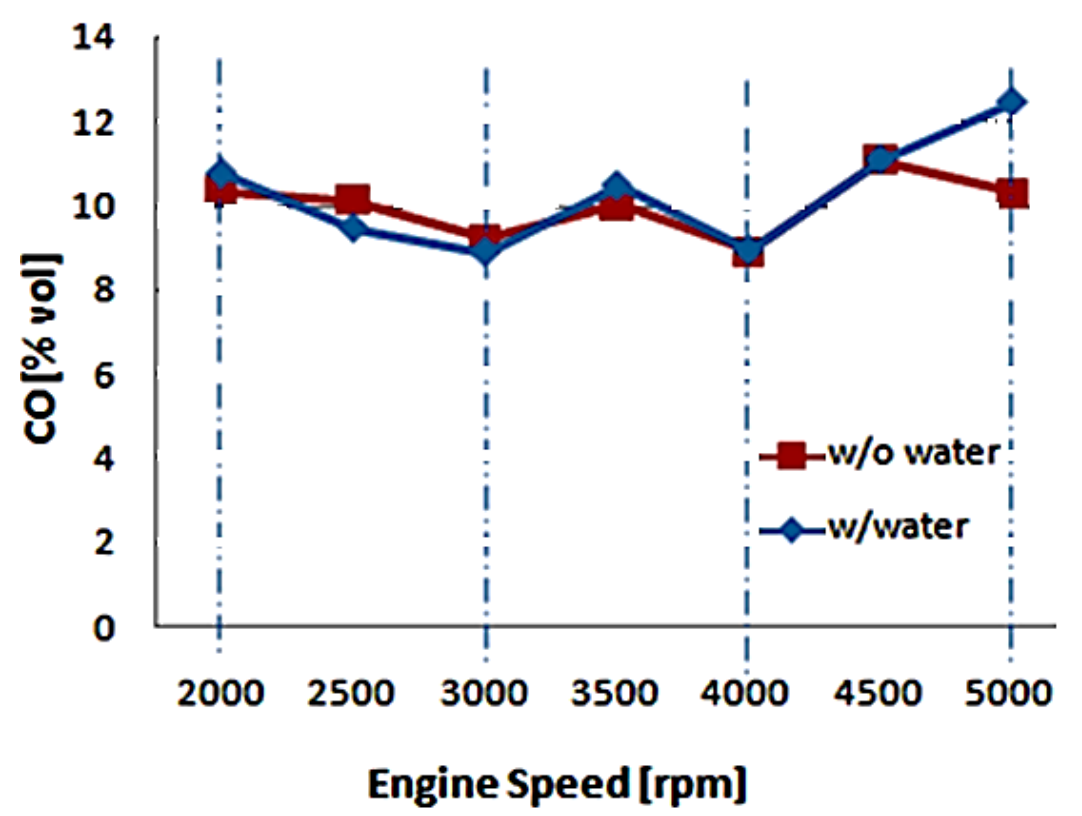

Figure 9. CO with and without WM injection.

\section{CONCLUSIONS}

Injection of water upstream of the engine cylinder has been numerically proved in this study. An experimental investigation of WM addition to the intake manifold of an SI engine was found to reduce the temperature of gases within the combustion chamber and the intake manifold resulting in high power densities and better fuel conversion efficiencies for the same limit of knocking and emission. The WM injection to the intake manifold of an engine increases engine performance, corrects the mass flow rate ratio, and also increases the volumetric efficiency due to the dissociation of water into hydrogen and oxygen caused by an increase in combustion pressure. Water mist was injected to the intake manifold just after the throttle flap trough a water addition unit; this reduced the exhaust gas emission. The direct injector does not affect the density of the air entering the cylinder, but permits the introduction of water before, during, and after the combustion event. This further reduces heat loss and increases the steam expansion process.

\section{ACKNOWLEDGMENTS}

The authors would like to thanks to Department of Mechanical Engineering, NIT, Warangal, 506004, India for financial assistance and laboratories facilities.

\section{REFERENCES}

[1] Aziz A, Rashid A, Firmansyah, Shahzad R. Combustion analysis of a CNG direct injection spark ignition engine. International Journal of Automotive and Mechanical Engineering. 2010;2:157-70.

[2] Hamada KI, Rahman MM. Experimental study performance emissions small four stroke SI engine modern motorcycle. International Journal of Automotive and Mechanical Engineering. 2014;10:1852-65. 
[3] Kamil M, Rahman MM, Bakar RA. An integrated model for predicting engine friction losses in internal combustion engines. International Journal of Automotive and Mechanical Engineering. 2014;9:1695-708.

[4] Boretti A. Water injection in directly injected turbocharged spark ignition engines. Applied Thermal Engineering. 2013;52:62-8.

[5] Harrington J. Water Addition to Gasoline-Effect on Combustion, Emissions, Performance, and Knock. SAE Technical Paper; 1982.

[6] Peters BD, Stebar RF. Water-gasoline fuels-their effect on spark ignition engine emissions and performance. SAE Technical Paper NO. 760547; 1976.

[7] Abdullah NR, Shahruddin NS, Mamat R, Ihsan Mamat AM, Zulkifli A. Effects of air intake pressure on the engine performance, fuel economy and exhaust emissions of a small gasoline engine. Journal of Mechanical Engineering and Sciences. 2014;6:949-58.

[8] Lanzafame R. Water injection effects in a single-cylinder CFR engine. SAE Technical Paper No. 1999-01-0568; 1999.

[9] Nicholls J, Ei-Messiri I, Newhali H. Inlet manifold water injection for control of nitrogen oxides - theory and experiment. SAE Technical Paper; 1969.

[10] Gunnerman RW. Aqueous fuel for internal combustion engine and method of combustion. Google Patents; 1992.

[11] Binion WS. In-cylinder water injection engine. Google Patents; 1998.

[12] Tsao K, Wang C, Miller E. Performance of gasoline-water fuel in a modified SI engine. SAE Technical Paper; 1984.

[13] Stanglmaier RH, Roberts CE. Homogeneous charge compression ignition (HCCI): benefits, compromises, and future engine applications. SAE Technical Paper; 1999.

[14] Hairuddin AA, Wandel AP, Yusaf T. An Introduction to a Homogeneous Charge Compression Ignition Engine. Journal of Mechanical Engineering and Sciences. 2014;7:1042-52.

[15] Mezheritsky AD, Halimi EM. Water/fuel mixing system for a gasoline engine. Google Patents; 1998.

[16] Özcan H, Söylemez M. Thermal balance of a LPG fuelled, four stroke SI engine with water addition. Energy conversion and management. 2006;47:570-81.

[17] Ballard BPSI. FCgen®-1310 Fuel Cell Stack. 2012.

[18] Aydin H, Bayindir H. Performance and emission analysis of cottonseed oil methyl ester in a diesel engine. Renewable Energy. 2010;35:588-92.

[19] Rahim R, Mamat R, Taib MY, Abdullah AA. Influence of fuel temperature on a diesel engine performance operating with biodiesel blended. Journal of Mechanical Engineering and Sciences. 2012;2:226-36.

[20] Ghobadian B, Najafi G, Nayebi M. A semi-empirical model to predict diesel engine combustion parameters. Journal of Mechanical Engineering and Sciences. 2013;4:373-82.

[21] Yusop AF, Mamat R, Mat Yasin MH, Ali OM. Effects of particulate matter emissions of diesel engine using diesel-methanol blends. Journal of Mechanical Engineering and Sciences. 2014;6:959-67.

[22] Fraser N, Blaxill H, Lumsden G, Bassett M. Challenges for increased efficiency through gasoline engine downsizing. SAE Technical Paper no. 2009-01-1053; 2009. 